\title{
To teach is to learn: high-school students, local university and informal science educators collaborate in communicating science to the public
}

Veronica Padovani ${ }^{1 *}$, Carlyn S Buckler ${ }^{1}$, Alessandro F Gualtieri ${ }^{2}$ and Alessandro Vescogni ${ }^{2}$

\begin{abstract}
Background: Informal education, especially if in collaboration with formal education, can be an important vehicle for communicating current research in science to the public as well as significant in drawing the young nearer to science and helping them to understand the inherent processes.
\end{abstract}

Methods: In this paper we describe an international collaboration between a group of high-school students in Italy and Earth scientists and museum professionals from Italy and the US to plan and implement a scientific exhibition on symmetry, a topic chosen because of its connections to both Earth science and evolution.

Results: By directly involving the high-school students in the design and implementation of the exhibition, they were given ownership of the project as well as 'hands-on' experience of communicating science to the public. The students involved helped design the content and layout of the exhibition, as well as with the design and fabrication of exhibition elements, marketing of the exhibition and evaluation. The design allowed the project manager to collect input from the students on how to make exhibitions more 'user friendly' to their age demographic, as well as to children and young adults in general. Although more research on similar projects is needed, evaluation results from this project showed that the response of the students - and of visitors - to the exhibition was significantly positive, and suggest that the project was engaging, cost effective and easy to implement.

Conclusions: This project may serve as a template for other formal and informal educators to develop these types of collaborations, using informal science education as a bridge to link science researchers and middle- and high-school students in creating an environment where students learn through actively participating in the public communication of science.

Keywords: Bottom-up approach, Communicating science, Evaluation, Exhibit, Informal science education, Symmetry

\section{Background}

Understanding Earth science is fundamental to understanding natural processes, particularly evolution, and is key to making informed decisions about current scientific concerns such as global climate change, resource depletion, and energy transitions (Bell 2009, Dobzhansky 1973). When natural disasters occur (e g., hurricanes, earthquakes,

\footnotetext{
* Correspondence: vp247@cornell.edu

${ }^{1}$ Paleontological Research Institution, 1259 Trumansburg Road, Ithaca, NY 14850, USA

Full list of author information is available at the end of the article
}

floods, droughts) or when local populations are asked to make crucial decisions regarding issues that involve Earth science (e.g., drilling for oil or natural gas, clear-cutting forests, designating protected natural areas, building a dam), the public must have an understanding of, and realistic expectations about, Earth science information; we must have an Earth science literate public (Kolstø 2001).

The philosophy in the past has been that elementary through high-school education is responsible for teaching and engaging children in science, thus creating a science literate public (Bell 2009). High-school students (i.e., the 
segment of the population from 14 to 18 years of age) are in a phase of their lives that is very important for the construction of their social conscience and career choices, making them a desirable target audience for science education initiatives (Gloeckner 1991). But it is also at this age that science literacy begins to decrease, as compared with K-5 students (National Science Board 2010). Research in the US shows that, although students in elementary school rank high in science literacy, science literacy drops significantly starting in middle school and continuing through high school (National Center for Education Statistics U.S. Department of Education 2010). In Italy, research on science literacy (Program for International Student Assessment 2010) ranked Italian 15-year-old students below the average of Organization for Economic Cooperation and Development countries (National Science Board 2010). In fact, both Italian and US students scored in the bottom quartile; US students ranking 19th and Italian students ranking 21st of the 25 developed countries surveyed (National Science Board 2010; tables one to eight). Furthermore, the same study found that only $15.6 \%$ of bachelor's degrees were awarded in science, technology, engineering and math (STEM) fields in the US, and the overall share of degrees awarded in STEM fields actually shrank during the period surveyed, from 2003 to 2007. Meanwhile, China awarded nearly half of its first university degrees in STEM fields (46.7\%), South Korea awarded 37.8\% and Germany awarded 28.1\% (National Science Board 2010; tables two to thirty-five).

Most K-12 schools do not have the extensive science collections and resources that would facilitate a better understanding of Earth science. These types of large, comprehensive collections are usually housed in universities and natural history museums where they provide a handson, inquiry-based means of participation in science. Unfortunately, most researchers at universities rarely, if ever, have the time or the expertise to organize and implement education to K-12 schools. Most museums, however, consider this their mission and have extensive outreach programs and years of experience engaging school groups in science. Bringing together science-rich cultural institutions and schools has been shown to substantially support children in realizing the relevance of science to their lives, and that they can engage in science to contribute to their communities (Bevan et al. 2010 and references therein). Informal science educators - such as educators from natural history museums or science centers - are specifically trained to communicate science to the public and school groups using collections and exhibitions. Because these educators understand the formal classroom environment, as well as how to engage people in science through collections and exhibitions, informal science educators are excellent candidates for facilitating collaborations between university and museum collections and resources and high-school classes to specifically engage this demographic in science and science careers.

Creating collaborations between universities, museums and local schools to engage high-school students in Earth science, and help them consider science as a possible vocation, thus seems a logical method of helping to alleviate many of the outlined issues. Moreover, learning often occurs in environments in which adults and peers guide students through active participation and assistance (Collins et al. 1989; Rogoff 1990). But certainly one of the best ways to gain knowledge about a subject is to teach others - as Frank Oppenheimer said, 'to teach is to learn'. By involving students in the public communication of a science topic, they have the opportunity to learn as they develop their content and vehicle of communication.

There are very few published studies or published examples of these types of collaborations. Although not involving students teaching science, two examples of similar partnerships are the SPARK! program in Philadelphia and the WATCH program at the Monterey Bay Aquarium in California. SPARK! is a National Science Foundation-funded collaboration between the Graduate School of Education and the School of Engineering and Applied Sciences at the University of Pennsylvania, the Philadelphia Zoo, and the Philadelphia city school district. The program, which focuses on engineering design, aims to help students understand design parameters for animal habitat construction (see Spark 2008). The WATCH program includes a three-week summer session where students work in teams to visit, study and restore habitats of the Pajaro River Watershed in California. The program also includes a school-year environmental science class where students participate in ongoing research of the watershed. In a 2006 study, pre- and postsurveys of $30 \mathrm{WATCH}$ program students - most of whom were Latino - found 'statistically significant changes in students' relationships to local ecologies, including their awareness of various environmental issues, and their import and impact for local communities' (Bevan et al. 2010). A published evaluation for the WATCH program also showed that $62 \%$ of WATCH participants reported that the program influenced their decision to go to college, as well as having an influence on their local conservation awareness and action (Parsons et al. 2011). It should be noted that these programs each have significant financial backing: SPARK! from an $\$ 800,000$ National Science Foundation grant, and WATCH from an institutional endowment, from which $\$ 6.7$ million went to education and visitor programs in 2011 (Monterey Bay Aquarium 2012). While these two studies do show that informal science educators can bridge the gap between university science research and local high-school students, clearly more examples need to be produced, and studies performed, to prove the efficacy and viability of this model. 
The goals for this project were to (a) increase awareness among students about their local university's Earth Science department; (b) engage local high-school students in communicating Earth science to the public; and (c) create a template for a successful collaboration between a local university Earth Science department, informal science educators and local high-school students to design, manufacture and implement an Earth science exhibition.

\section{Methods}

To address these issues, the Earth Science Department of an Italian university initiated a collaboration with a local high school ${ }^{\mathrm{a}}$ involving a group of high-school students, university Earth scientists and museum professionals to plan and implement a scientific exhibition on the subject of symmetry - chosen for its connection to both Earth science and the evolution of life on Earth. This exhibition ran for two weeks at the school, and the entire project lasted approximately six months. (For the complete protocols, evaluations, surveys and statistics for the project, see, Earth System Science Informal Education Network 2008).

There are several criteria to consider when undertaking a collaboration with any K-12 school. Most teachers schedule class time very tightly, and have little time for extracurricular activities. Curriculum, too, needs to be considered because most teachers have activities and lessons planned months in advance. Another important requirement is cost effectiveness of the program. For this project, in an effort to be respectful of teachers' and students' time schedules and curricula, most meetings were planned outside regular school hours and with minimal help from teachers. Initial contact with the students was made through the school's headmaster and with the teacher responsible for university counseling to define the partnership in terms of resources, timetable and compatibility with the students' curriculum.

The current global economic crisis has created a significant drop in available funds for Italian public schools and universities - as is also the case in the US - so the project needed to be very modest in cost. The entire project required 800 EUR (at the time, less than 1,000 USD) in eligible costs for printing panels, which was funded by the university. Specimens and specimen cases were part of the university's scientific collection, and the exhibition was held in a classroom at the high school, hence requiring no facility rental fees. Because of the generic nature of the panels and other materials, these resources were reused and repurposed several times in the subsequent years in other educational and outreach events at the university. Printing the panels in-house on soft paper or other rigid material could further cut costs, although the use of a more substantial material would facilitate re-use of the panels.
The project spanned a period of six months, and began with a presentation by an Earth scientist from the university and a museum professional (who organized and managed the project) to five third-year classes (students ages 16 years old) at the Liceo Scientifico high school. Italian high-school students in their third year of school have not yet dealt with Earth sciences in their science curriculum (Earth sciences are part of the fifth year science syllabus). The presentation gave an overview of and goals for the project, together with relevant insights on the activities conducted at the Earth Sciences Department at the university. Students who were interested in the project were asked to enroll by sending a motivation letter via email to the informal science educator. Twenty-five students participated in the first meeting of the project, held at the Earth Science Department, which addressed the outline of the project and planning of the exhibition. During the meeting, students were also given basic information on informal science education and an explanation of the phases of exhibition planning (from Houtgraaf and Vitali 2008). The second meeting (two weeks later) was aimed at giving the students essential knowledge on symmetry as related to Earth science. Two scientists from the university a mineralogist and a paleontologist - showed the students numerous mineral and fossil samples from the Department's collection, and students were encouraged to ask questions and interact with the presenters throughout the lessons. Both scientists carried on their collaboration with the project by giving continuous feedback throughout the exhibition development and implementation process. They were often present at the meetings (the structure of which they collaborated on) and offered their advice to students during office hours and via email.

The ensuing meetings followed the first three steps of exhibition planning - concept, storyline and design. Students were asked to provide first drafts on the conceptual planning of the exhibit (exhibit titles, core ideas, storyline, signage content, choice of objects and concepts, and advertising strategies) both during the meetings and via email. The students defined the big ideas of the exhibition by first making statements individually and then discussing amongst the group to come to consensus. The title of the exhibition 'Sim(meet)ria: l'ordine incontra la natura' (Sym(meet)ry: order meets nature) was conceived by a student.

The exhibition text was finalized by the museum professional after a consensus was reached with the students on the storyline and content of the exhibit. Content was then reviewed by the university scientists, who checked for scientific accuracy. The students performed a final review of all exhibition text and were asked to point out unclear passages or jargon in an effort to make the text more readable. The students also provided feedback, contributed to the graphics and physical layout of the exhibit, and defined 
and carried out marketing strategies (design and distribution of flyers and a poster, design and use of a Facebook page, etc.).

All of the meetings were held at the university's Earth Sciences Department facilities, where students were encouraged to visit the Department's geology museum and examine the mineral and fossil collections to select the specimens to exhibit. The fabrication of the exhibition was performed by all participants, including students, the museum professional and scientists.

The exhibit was installed in a classroom at the school and was open to the public for two weeks from Monday to Saturday, mornings and afternoons. During the exhibition, students gave guided tours to the visitors - many of whom were fellow students and their parents - acting as docents for their classmates in the morning and for the general public in the afternoons.

A total of 632 people (the majority high-school students) visited the exhibition. Fifteen students completed the program by collaborating actively in the design, content development and installation of the exhibition. The involvement of these students was made explicit in the exhibit and during the opening ceremony. All of the participating students were given a certificate valid for obtaining school credits at the end of the term.

\section{Results and discussion}

Evaluation for this project included (1) a summative evaluation survey of participating students, (2) a student focus group, (3) a survey of the visitors to the exhibition, and (4) a two-year follow up post-survey of participating students.

(1) Summative evaluation. After their participation in the design of the exhibition, but before the exhibition was installed and opened to the public, the students were requested to complete an anonymous online survey concerning their participation in the project. The participating student survey was designed to collect data on the students' attitudes towards science as a school subject and on their response to the project. Out of the 15 students who fully participated in the planning phase, 12 completed the anonymous survey.

Overall, the responses of the students to the project were very positive, and the suggestions and comments were constructive and thoughtful. It is of note that many students reported an interest in objects rather than topics, by citing 'fossils' and 'minerals' as most interesting, instead of 'paleontology' and 'mineralogy'. This result indicates that working with objects - fossil and mineral specimens made a strong impression on the participants and reinforces the idea that objects are powerful educational media. With regard to skills they thought they developed or improved during the project, most of the students mentioned organizational skills, and others pointed out that they learned new things about science. Most of the students provided comments or suggestions, such as creating a blog site for the project.

(2) Student focus group. The day before the exhibition was installed, a meeting with the student participants was organized to collect further impressions on the project. Students were asked to give their impressions via an oral survey on the experience of working on an exhibition. Eleven students of the original 15 were present and gave their feedback on particular aspects of the project.

One of the most common responses from students involved in the project was that they liked the team environment and the active involvement in creating the exhibit, indicating a significant engagement level with the project. The students also stated they felt they had been 'behind the scenes' and thus were now motivated to visit an exhibition that perhaps they would not have before their participation in the project. Another student pointed out that skills learned from being involved in exhibition planning - such as getting a particular audiences' attention (marketing) or making topics interesting to other people (communicating science to the public) are also useful in everyday life.

(3) Visitor survey. Visitors' questionnaires were aimed at gaining information about the demographics, the knowledge gained from the exhibit and about the local university Earth Sciences Department, and favorite elements of the exhibit as well as comments and critiques. Of the 632 visitors that attended the exhibition, 224 surveys were collected. Visitors' comments revealed a rather surprising insight; almost half of the visitors who provided a response to 'further comments' suggested enlarging and/or enriching the exhibit. In other words, this audience, composed mainly of high-school students, wanted to see more specimens and content in the exhibition. This contradicts the rather deeprooted assumption that, when dealing with younger audiences, brevity and extreme conciseness is mandatory (Barnard and Loomis 1994).

(4) Student post-survey. Two years after the completion of the project, during the summer before the students' enrollment in university courses, participants were contacted via Facebook to answer three questions: in which university courses, if any, they will enroll; if the project proved to be a useful experience in the subsequent school years; and which was the most significant (and useful) activity they remembered from the project. Of the original 15 participants, 10 gave their feedback. The post-survey showed student appreciation for having had contact with the university environment so early in their education. The vast majority of respondents (80\%) also reported that the knowledge acquired during the project was helpful for them in carrying out the science syllabus during subsequent school years. Although none of the respondents declared to have chosen 
Earth science as a career, this project may still have served to familiarize them with Earth science and where reliable information on Earth science issues can be obtained. Again, more examples and study of similar projects would need to be carried out.

In 2012, the school where the exhibition was held requested, for the first time, the participation of the participating university's Earth Science Department in an academic orientation day, which represents a positive outcome in terms of institutional partnerships and recognition.

\section{Conclusions}

The authors acknowledge that a more robust evaluation process, in particular a more thorough understanding of a priori knowledge of the students' Earth science and evolution knowledge, would be beneficial to further affirm the efficacy of such projects. More study also needs to be done with larger groups, and surveys of teachers regarding their attitudes towards the project would also benefit the template.

Giving high-school students the opportunity to 'teach' science to the public and their peers through such a collaborative effort has the potential to offer a foundation for identities as scientists, and allow them to have firsthand experience in gathering reliable scientific information to teach others about Earth science. The project, being cost effective, easy to carry out and minimally invasive on teachers', scientists' and students' time, makes this project applicable to most science museums or other science-rich institutions in possession of a scientific collection.

By involving the students directly in the design and implementation of this science exhibition, they were given ownership of the project (O'Neill 2005) as well as a hands-on experience with communicating science to the public. The design also allowed for input by the students on how to make exhibitions more user friendly for their age demographic, as well as to children and young adults. This preliminary data provides a good bottom-up source of suggestions for improvements for future collaborations with high-school students, and shows that the basic design of this project may be used as a template for future collaborations between informal science educators, scientists and schools. The long-term data on how these types of programs can affect participants will be important for informing future collaborations as well as funding for such programs.

\section{Endnote}

${ }^{\mathrm{a}}$ In Italy, the second level of secondary education (high school) varies, because there are several types of schools differentiated by subjects and activities. The school involved in this study was a 'Liceo Scientifico', whose program includes subject requirements in Italian, Latin, history and philosophy, and an emphasis on mathematics, physics and the natural sciences.

\section{Competing interests}

The authors declare that they have no competing interests.

\section{Authors' contributions}

VP organized and managed the project and drafted the manuscript. CSB was thesis advisor to VP, and contributed to project design, directed design, summary and conclusions from evaluation, and contributed content and editing for this paper. AFG curated the educational content regarding mineralogy and contributed to project design and content and editing for this paper. AV curated the educational content regarding paleontology and contributed to project design and content and editing for this paper. All authors read and approved the final manuscript.

\section{Author details}

${ }^{1}$ Paleontological Research Institution, 1259 Trumansburg Road, Ithaca, NY 14850, USA. Dipartimento di Scienze della Terra, Largo S. Eufemia 19, 41121, Modena, Italy.

Received: 27 January 2013 Accepted: 27 January 2013

Published: 26 March 2013

\section{References}

Barnard, WA, \& Loomis, RJ. (1994). The museum exhibit as a visual learning medium. Visitor Behavior, Special Issue: Memory, 9(2), 14-17.

Bell, P. (2009). Learning science in informal environments: People, places, and pursuits. Washington DC: National Academies Press.

Bevan, B, Dillon, J, Hein, GE, Macdonald, M, Michalchik, V, Miller, D, Root, D, Rudder, L, Xanthoudaki, M, \& Yoon, S. (2010). Making science matter: Collaborations between informal science education organizations and schools (A CAISE Inquiry Group Report). Washington D.C: Center for Advancement of Informal Science Education (CAISE).

Collins, A, Brown, JS, \& Newman, S. (1989). Cognitive apprenticeship: teaching the crafts of reading, writing, and mathematics. In LB Resnick (Ed.), Knowing, learning, and instruction (pp. 453-494). Hillsdale, NJ: Erlbaum.

Dobzhansky, T. (1973). Nothing in biology makes sense except in the light of evolution. Am Biol Teach, 35(3), 125-129.

Earth System Science Informal Education Network. (2008). Earth System Science Informal Education Network homepage. http://www.informalearthscience.us/ news/news/to-teach-is-to-learn.html.

Gloeckner, G. (1991). The integration of science, technology, and mathematics: Myth or dream? J Technol Educ, 2(2), 75-81.

Houtgraaf, D, \& Vitali, V. (2008). Mastering a museum plan: strategies for exhibit development. Leiden, Netherlands: Naturalis.

National Science Board. (2010). Science and Engineering Indicators 2010 Arlington. Tables 1-8. http://www.nsf.gov/statistics/seind10/start.htm. Accessed 30 August 2012.

Kolstø, SD. (2001). Scientific literacy for citizenship: tools for dealing with controversial socio-scientific issue. Sci Educ, 85(3), 291-310.

Monterey Bay Aquarium. (2012). Monterey Bay Aquarium Annual Review 2011. http://www.montereybayaquarium.org/PDF_files/aa/financials/ aquarium_annualreview_11.pdf. Accessed 30 August 2012.

National Center for Education Statistics U.S. Department of Education. (2010). Digest of Education Statistics. http://nces.ed.gov/programs/digest/d10/ch_2. asp. Accessed 30 Aug 2012.

O'Neill, T. (2005). Uncovering student ownership in science learning: The making of a student created mini-documentary. School Science and Mathematics, 105(5), 292-301.

Parsons, C, Bell, R, \& Swan-Sofsky, K. (2011). Watsonville Area Teens Conserving Habitats (WATCH) Connecting with their community's watershed. Children, Youth and Environments, 21(1)

Rogoff, B. (1990). Apprenticeship in thinking. New York: Oxford University Press. Spark. (2008). About SPARK! http://www.gse.upenn.edu/spark/about.php.

\section{doi:10.1186/1936-6434-6-7}

Cite this article as: Padovani et al:: To teach is to learn: high-school students, local university and informal science educators collaborate in communicating science to the public. Evolution: Education and Outreach 2013 6:7 